the use of safety equipment, which can also be true for us since we found that our participants conserve some risky habits such as recapping and manual needle mismatching.

Conclusion Steady efforts should be taken to counter attack the growing numbers of ABE. We need to reinforce information and training methods aimed at healthcare workers, and we also have to promote vaccination in healthcare settings.

\section{OCCUPATIONAL EXPOSURE TO BLOOD AND BODY FLUIDS: KNOWLEDGE, ATTITUDE AND PRACTICES AMONG NURSES AT IBN ROCHD UNIVERSITY HOSPITAL OF CASABLANCA}

I El Amri*, D Lahlou, B Benali, A El Kholti. Casablanca Faculty of Medicine and Pharmacy, Hassan II University, Morocco

\subsection{6/oemed-2018-ICOHabstracts.921}

Introduction Our study was conducted to describe prevalence and risk factors for occupational exposure to blood and body fluids (BBF) among nurses and to evaluate their knowledge, attitude and practices concerning blood-borne pathogens and adherence to universal safety precautions.

Methods From March 2016 to October 2016, we’ve conducted a survey amongst nurses working at Ibn Rochd University Hospital of Casablanca. The questionnaire recorded socio demographic characteristics, information about working experience, questions assessing knowledge about blood-borne pathogens, the action to be taken after an accident and questions about standard precautions.

Results We had 110 respondents, 74,5\% have been working for more than a year, 58,3\% never had training courses about occupational exposure to BBF and $40,4 \%$ had already experienced at least once in their working life an accident exposing them to BFF. Of those, only 7 reported the accident at every time. Only 9\%, 6,3\% and 9,9\% knew the respective seroconversion rates for HBV, HCV and HIV and 37,6\% admitted never hearing about universal precautions.

Discussion Overall, participants' knowledge about BBF exposure accidents was inadequate. we also found that some participants did not know about the right procedures to take after being exposed. We thought that this can be placed on the lack of information, so we've decided to conduct this survey before and after an informational course that we've organised at the occupational health department. Unfortunately, we couldn't gather enough data after the course because of the lack of respondents.

Conclusion Health care workers should be made aware of the risks of infection they may acquire from these accidents by educating them while they're still students. Additional educational courses should be provided at a regular basis to enhance the awareness and help the workers stay up to date. HBV vaccination should be encouraged for nurses before taking any practical training.

\section{OCCUPATIONAL HEALTH DEVELOPMENTS IN KENYA'S HEALTH SECTOR}

Kibor Kipkemoi Keitany. Ministry of Health, Nairobi, Kenya

10.1136/oemed-2018-ICOHabstracts.922
Introduction The advancement is healthcare is a product of international and local policies, guidelines and recommendations. Occupational Health is a key aspect in sustainable development by ensuring safe work environment and a motivated healthy workforce. Focus has been directed more on factory set up and less on health sector. Recent developments internationally and locally strive at provision of occupational health services to workers in all sectors. This paper review aimed at finding out the developments in occupational health in the health sector in Kenya.

Method The study utilised secondary data. These were obtained from local, national and international organisations. International information obtained from science publication, ILO, WHO, ICOH and other organisations advocating for best practices. National policies, policy guidelines and other grey literature and government publications from Ministries Labour and Ministry of Health were utilised.

Results The interventions to protect the health of healthcare workers include legislations, guidelines and training on occupational safety and health; Infection prevention and control; healthcare waste management; Vaccinations and post exposure prophlaxis. Kenya has progressed from her first legislation on occupational health that focused only on factories to current target of all workplaces. Healthcare workers' safety and health took centre stage with the publication of occupational safety and health risk assessment report in February 2013. It was a product of nationwide survey on state owned health facilities that revealed several health hazards faced by healthcare workers.

Discussion There are notable advancements in occupational Health in health sector in Kenya. This has been guided mainly by recommendations, resolutions and conventions of WHO and ILO. The transition from Factories Ordinance of 1950, to current Occupational Safety and Health Act, 2007 and Work Injury Benefits Act of 2007 has contributed to better enforcements in the health sector. Slow progress may be attributed to funding and human resource limitations

\section{IS HOSPITAL SANITATION PERSONNEL EXPOSED TO ANTINEOPLASTIC AGENTS?}

${ }^{1,2} \mathrm{~F}$ Labrèche ${ }^{*}$, ${ }^{1} \mathrm{~B}$ Roberge, ${ }^{1} \mathrm{~A}$ Yennek, ${ }^{3} \mathrm{NJ}$ Caron, ${ }^{4,5} \mathrm{~J}$-F Bussières. ${ }^{1}$ Institut de recherche Robert-Sauvé en santé et en sécurité du travail (IRSST), Montréal, QC, Canada; ${ }^{2}$ School of Public Health, Université de Montreal, Montréal, QC, Canada; ${ }^{3}$ Centre de toxicologie du Québec, Institut national de santé publique du Québec, Québec, QC, Canada; ${ }^{4}$ Pharmacy Practice Research Unit, Pharmacy department, CHU Sainte-Justine, Montréal, QC, Canada; ${ }^{5}$ Faculty of pharmacy, Université de Montréal, Montréal, QC, Canada

\subsection{6/oemed-2018-ICOHabstracts.923}

Introduction Exposure to antineoplastic drugs (ANPs) occurs mainly through dermal contact. In hospital settings, pharmacy and nursing personnel are considered the most exposed workers and receive training on handling dangerous drugs. There is, however, little data on exposure of hospital sanitation (HS) personnel. Our main objective is to document the potential exposure of HS personnel by exploring surface contamination. Methods Following a preliminary visit to identify target surfaces, 75 wipe samples were taken on surfaces often touched by the HS personnel and 21 samples on other hi-touch surfaces, in three oncology departments: pharmacy, outpatient clinic and hospital ward. Sampled areas varied from $160-1700 \mathrm{~cm}^{2}$. A few hand wipe samples were also collected to explore skin 
contamination. Wipes were analysed by ultra-performance liquid chromatography tandem-mass spectrometry for 10 ANPs. Limits of detection (LOD) varied by a factor of 10 according to sampled area and ANP. Descriptive statistics are presented here.

Result Overall, 11 of the 16 types (68.8\%) of sampled surfaces were above the LOD for at least one ANP; gemcitabine and cyclophosphamide were most often identified $(30.6 \%$ and $29.8 \%$ of samples respectively), followed by 5 -fluorouracil and irinotecan (both 15.6\% above LOD). Highest levels were all found in the outpatient clinic: 5-fluorouracil $\left(49 \mathrm{ng} / \mathrm{cm}^{2}\right)$ and irinotecan $\left(3.6 \mathrm{ng} / \mathrm{cm}^{2}\right)$, toilet floor; cyclophosphamide (19.6 $\left.\mathrm{ng} / \mathrm{cm}^{2}\right)$, IV pump; gemcitabine $\left(4.97 \mathrm{ng} / \mathrm{cm}^{2}\right)$, cytotoxic waste bin cover. Hand wipes were above the LOD for five of seven nurses, one of seven pharmacy personnel and none of three sampled HS workers.

Discussion A notable proportion of surfaces showed measurable levels of ANPs, with highest concentrations on surfaces cleaned by HS personnel. Prevention programs should integrate regular monitoring of hospital surfaces in order to evaluate environmental contamination and sharing monitoring results with all concerned personnel, together with appropriate training, in order to raise their awareness of ANP exposures.

\section{APPRAISAL OF WORK ABILITY IN RELATION TO JOB- SPECIFIC HEALTH REQUIREMENTS IN AMBULANCE WORKERS}

1,2 van Schaaijk, ${ }^{1,2}$ JS Boschman, ${ }^{1,2} \mathrm{MHW}$ Frings-Dresen, ${ }^{1,2} \mathrm{JK}$ Sluiter. ${ }^{1}$ Coronel Institute of Occupational Health, Academic Medical Centre, Amsterdam, The Netherlands; ${ }^{2}$ Amsterdam Public Health research institute, Amsterdam, The Netherlands

\subsection{6/oemed-2018-ICOHabstracts.924}

Introduction To gain insight into which job-specific health requirements relate to self-estimated work ability, the following two research questions were formulated: Which job-specific health requirements are associated with the appraisal of work ability in ambulance drivers and paramedics? How are appraisals of physical and mental work ability associated with the appraisal of overall work ability in ambulance drivers and paramedics?

Methods Workers Health Surveillance cross-sectional data of 506 ambulance workers (236 drivers and 270 paramedics) were used. The outcomes for specific job requirements were divided into six categories; 'having raised alertness and judgment ability', 'dealing with emotional peak load', 'to perceive and communicate', 'job-specific physical abilities', 'skin complaints' and 'respiratory complaints'. Work ability was appraised as overall, physical and mental/emotional. Multiple linear stepwise regression analyses were used to model the associations.

Result Outcomes in 'raised alertness and judgment ability' $(\mathrm{R} 2=0.09)$, ‘job-specific physical abilities' $(\mathrm{R} 2=0.10)$ and 'emotional peak load' $(\mathrm{R} 2=0.07)$ significantly explained appraised overall, physical and mental/emotional work ability $(\mathrm{p}<0.01)$. Physical and mental/emotional work ability together explained $48 \%$ of the variance in overall work ability. The explained variance by physical and mental/emotional work ability was almost $4 \%$ higher in drivers than in paramedics.

Discussion The appraisal of overall work ability was significantly explained by outcomes in 'raised alertness and judgment ability' and 'emotional peak load.' Physical work ability was significantly explained by 'job-specific physical abilities' and 'raised alertness and judgment ability' outcomes, while 'emotional peak load' and 'raised alertness and judgment ability' outcomes significantly explained mental/emotional work ability. Physical and mental/emotional work ability explain the same proportion of variance in overall work ability.

\section{HEALTH CARE WORKERS' SAFE PATIENT HANDLING AND MOVEMENT KNOWLEDGE: A CROSS-SECTIONAL STUDY IN A DEVELOPING COUNTRY}

João Marcos Bernardes*, Adriano Dias. Botucatu Medical School/UNESP, Botucatu, Brazil

\subsection{6/oemed-2018-ICOHabstracts.925}

Introduction Healthcare workers worldwide present a high prevalence and incidence of low back pain due to manual patient handling tasks. Although education encourage the use of safe patient handling procedures, there is a lack of research about safe patient handling knowledge in developing countries. Therefore, the purpose of this study was to examine both levels of knowledge and factors associated with a good knowledge score among healthcare workers of a developing country. Methods This was a cross-sectional study with 292 healthcare workers from the University Hospital of Botucatu Medical School. A knowledge score was generated based on participant responses to a structured questionnaire, with a score of $70 \%$ or higher indicating good knowledge. Frequency statistics and logistic regression were conducted to analyse the data.

Result The majority of participants did not achieve a good level of knowledge (81,5\%). Only 54,1\% were aware of the high risk presented by patient-handling tasks. Most participants $(84,8 \%)$ were not knowledgeable of the recommended maximum weight limit for use in patient-handling tasks, $62,3 \%$ and $53,4 \%$ answered that relying on proper body mechanics and that the use of back belts are effective prevention methods, respectively. The knowledge gap was most prominent in the domain of safe patient handling, only $2,4 \%$ of participants answered correctly all questions regarding this topic. Regarding the associated factors towards a good level of knowledge, the only significant relationship in univariate as well as multiple logistic analysis was level of education, being less educated - elementary or high school education - was a significant predictor of lower levels of knowledge $(\mathrm{OR}=4.776$, 95\% CI: 1.056 to 21.600$)$.

Discussion A substantial knowledge deficit was identified among healthcare workers in our study. Policies and education campaigns to increase knowledge and improve preventive practices should be developed.

\section{PREVALENCE OF THYROID DISEASES IN AN OCCUPATIONALLY RADIATION EXPOSED GROUP: A CROSS-SECTIONAL STUDY IN A UNIVERSITY HOSPITAL OF SOUTHERN ITALY}

${ }^{1} \mathrm{~L}$ Vimercati*, ${ }^{1} \mathrm{P}$ Lovreglio, 'L De Maria, ${ }^{2} \mathrm{~V}$ Luisi, , $\mathrm{GM}$ Ferri, ${ }^{3} \mathrm{~F}$ Cuccaro, ${ }^{1} \mathrm{M}$ Quarato, ${ }^{1} \mathrm{~L}$ Soleo. ${ }^{1}$ Interdisciplinary Department of Medicine, University of Bari Medical School, Bari, Italy; ${ }^{2}$ Occupational Health Unit, 'Azienda Ospedaliero-Universitaria Consorziale Policlinico di Bari', Bari, Italy; ${ }^{3}$ Health Local Unit of Barletta-Andria-Trani, Barletta, Italy

\subsection{6/oemed-2018-ICOHabstracts.926}

Introduction Thyroid diseases occur more frequently in people exposed to ionising radiation (IR) for therapeutic purposes 